\title{
Evaluation of recent activity at Satsuma-Iwojima —Felt earthquake on June 8, 1996-
}

\author{
Masato Iguchi ${ }^{1}$, Eiji Saito ${ }^{2}$, Yuji Nishi ${ }^{2}$, and Takeshi Tameguri ${ }^{1}$ \\ ${ }^{1}$ Sakurajima Volcano Research Center, Disaster Prevention Research Institute of Kyoto University, Sakurajima, Kagoshima 891-1419, Japan \\ ${ }^{2}$ Geological Survey of Japan, Higashi 1-1-1, Tsukuba 305-8567, Japan
}

(Received July 10, 2000; Revised January 18, 2001; Accepted February 15, 2001)

\begin{abstract}
Emission of large amount of volcanic gas occurs at the summit crater of Satsuma-Iwojima volcano located south of Kyushu, Japan. Sakurajima Volcanological Observatory (SVO), DPRI, Kyoto University has conducted seismic observation at a permanent station $1.5 \mathrm{~km}$ WNW of the summit crater since June 1995. Volcanic earthquakes at the volcano are classified into A-type (high frequency), B-type (low frequency), C-type (monochromatic) and tremor. A-type earthquake generated by shear fracture and B-type earthquake with volumetric source are dominant at the volcano. Volcanic activity of Satsuma-Iwojima was evaluated from seismicity of the volcanic earthquakes. During the period of 1995-1998, the seismicity has remained at a constant level with seismic energy release rate of $7 \times 10^{14}$ erg/year. The seismicity was as high as that during 1975-1977. The energy release rate of volcanic earthquakes at the volcano has been stable at least for recent 20 years. Within the stable activity, a minor increase in activity occurred in mid-1990's, as shown by a felt earthquake (M2.9) on June 8, 1996. The earthquake on June 8, 1996 may be related to topographic changes and ground deformation around the summit crater, because a crack with length of $100 \mathrm{~m}$ was found at southeast rim of the summit crater in October 1996 and the benchmark near the crack moved eastward by $6 \mathrm{~cm}$ during the period from June 1995 to April 1997. The stable activity for 20 years and minor inflation of activity estimated from seismic observation coincides with those from $\mathrm{SO}_{2}$ flux, highest fumarolic temperatures and gas equilibrium temperatures. Although daily number of B-type earthquakes with smaller amplitude increased almost 10 times in September 1998, this increase in the seismicity did not accompany any change of eruptive activity. Unstable seismicity of B-type earthquake may reflect fluctuations of condition in the gas conduit.
\end{abstract}

\section{Introduction}

Satsuma-Iwojima is an island volcano located south of Kyushu, Japan (Fig. 1(A)). It is situated on the northwestern rim of the Kikai caldera, where a catastrophic eruption occurred 6,300 years ago (Matsumoto, 1943). A submarine eruption occurred in 1934-1935 and a new islet, ShowaIwojima was formed by lava extrusion from the sea bottom $2 \mathrm{~km}$ east of Satsuma-Iwojima. Over the last 1,000 years, fumarolic activity has continued at the summit crater of Mt. Iwodake, located in the eastern part of the island and volcanic ash has frequently been erupted from the crater.

Several volcano observations have been made at the volcano. Kamo (1976, 1977, 1978) conducted seismic observations by installing a tripartite network at the northwestern flank and determined hypocenter locations of volcanic earthquakes at a depth of $1 \mathrm{~km}$ around Mt. Iwodake. Repeat observation of topographic changes of the summit crater, analysis of volcanic gas and temperature measurement of fumarolic gas have also been made (Geological Survey of Japan, 1997). Ohminato and Ereditato (1997) recorded long-period seismic pulses during a dormant period of volcanic tremor activity and inferred that the long-period waves

Copy right (C) The Society of Geomagnetism and Earth, Planetary and Space Sciences (SGEPSS); The Seismological Society of Japan; The Volcanological Society of Japan; The Geodetic Society of Japan; The Japanese Society for Planetary Sciences. are related to magma convection in the volcanic conduit.

Continuous observation of volcanic earthquakes was conducted experimentally by Sakurajima Volcanological Observatory (SVO), Disaster Prevention Research Institute of Kyoto University using a 3-component seismometer and dialup telemetering system with PC in 1988 (Iguchi, 1991), and the continuous observation commenced in 1995 after 5 years-suspension of the observation. Most of the earthquakes observed at Satsuma-Iwojima volcano occur around the Mt. Iwodake and are too small to be felt (Kamo, 1976, 1977), however, an earthquake, which occurred on June 8, 1996, was M2.9 and was felt. After this earthquake, topographic changes at the summit crater of Mt. Iwodake were found and ground deformation around the summit was detected by GPS measurement.

In this paper, we summarize and evaluate the seismic activity of Satsuma-Iwojima volcano for the years from 1995 to 1998 and compare it with seismicity in 1975-1977. In addition, we discuss the significance of the felt earthquake on June 8, 1996 by using seismic and ground deformation data at the volcano.

\section{Observations}

Locations of seismic stations and GPS benchmarks are shown in Figs. 1(B) and 1(C), respectively. SVO installed a seismic station $1.5 \mathrm{~km}$ west-northwest of the summit crater, 

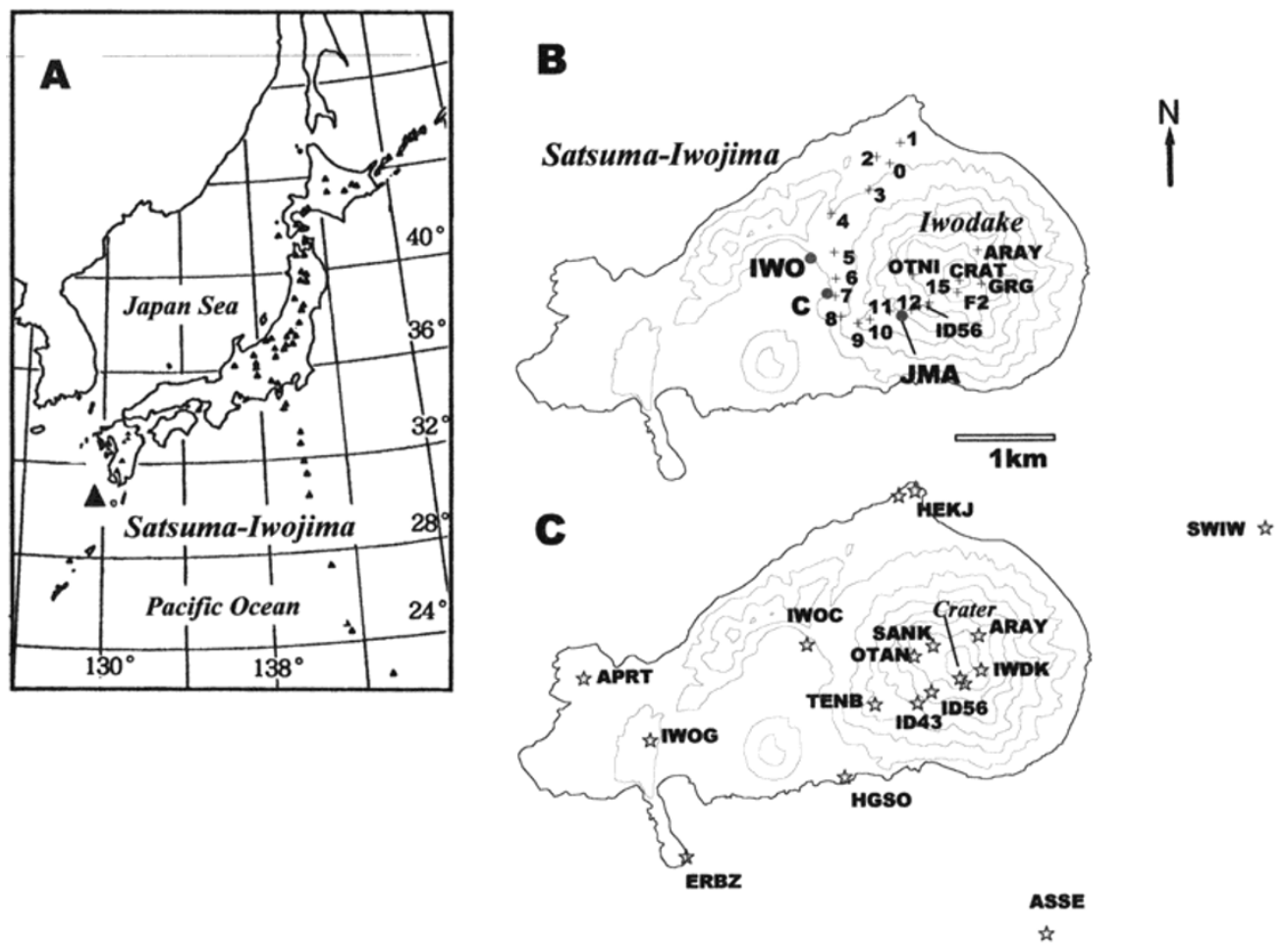

Fig. 1. Volcano observation networks at Satsuma-Iwojima. The location of Satsuma-Iwojima is shown in (A) and the locations of seismic stations and GPS benchmarks are shown in (B) and (C), respectively. Solid circles indicate stations for long-term observation. Station IWO is a permanent seismic station installed by SVO since June 1995. Station JMA has been operated by FDMO since September 1997. Station C was operated from June 1995 to January 1978 (Kamo, 1976, 1977, 1978). Crosses indicate temporary stations. The stations with numbers (0-15) were operated during the periods July 26-31, 1998 and November 14-25, 1999 by SVO. The stations ARAY, IWDK, F2, OTAN, ID56, CRAT were operated by GSJ in November 1999. The stars represent GPS stations and benchmarks. The GPS station IWOG is a permanent site installed in August 1994, and is also used as a relay station for telemetry. The contour interval is $100 \mathrm{~m}$.

equipped with a short-period $(1 \mathrm{~Hz}), 3$-component seismometer (station IWO). The seismic signal is transmitted to the relay station IWOG by radio and then transferred to SVO via telephone line (Iguchi, 1991). Fukuoka District Meteorological Observatory (FDMO) installed seismic stations around Mt. Iwodake temporarily, and the signals are transmitted to FDMO by using radio and telephone lines (Uchida and Sakai, 2002). The station JMA has been installed for long-term monitoring (Fig. 1(B)).

Fifteen stations (numbers 0 to 15 ) were installed by SVO to determine hypocenters of volcanic earthquake in July 1998 and November 1999. At these stations, signals from short-period (1 or $2 \mathrm{~Hz}$ ) sensors with vertical component were recorded on DATAMARK LS-8000SH data loggers. The stations ARAY, IWDK, F2, OTAN, ID56, CRAT were installed by Geological Survey of Japan (GSJ) in November 1999 to investigate volcanic earthquakes related with gas convection in the conduit. They used CMG-40T broadband seismometers and data loggers.

A permanent GPS station has been installed at IWOG, on the rim of the Kikai caldera, for continuous monitoring of the Kirishima volcanic belt (Kamo et al., 1997). In order to detect ground deformation at Satsuma-Iwojima Volcano and Kikai caldera, seven benchmarks were installed around the volcano by SVO in June 1995, and six benchmarks were added close to the summit crater to observe deformation of the crater area by GSJ in April 1997. Furthermore, two benchmarks were installed on the rock of lava domes above sea level (ASSE and SWIW) in November 1999. GPS measurements were conducted in June 1995, April, July, November 1997, March and July 1998, and July and November 1999. We used Leica SR399 and SR299E dualfrequency GPS receivers and the GPS data were recorded with a time interval of $15 \mathrm{~s}$ for 30 minutes to 3 hours. Baseline analysis was made by using SKI 2.1-2.3 software.

\section{Characteristics of Volcanic Earthquakes}

The observed earthquake waveforms at Satsuma-Iwojima are classified into 4 types; A-type, B-type, C-type and volcanic tremor (Iguchi et al., 1999). A-type earthquakes are high-frequency events with clear $\mathrm{P}$ and S-waves. Btype earthquakes are dominated by lower frequency seismic waves. C-type events are monochromatic with a peak frequency of $6.5 \mathrm{~Hz}$. C-type events have two patterns of waveform envelope; spindle-shaped and a long coda shape similar to T-type events at Asama volcano (Hamada et al., 1976). A-type and B-type earthquakes are dominant at the volcano. Typical waveforms of A-type and B-type volcanic earthquakes observed at several stations are shown in Fig. 2. High-frequency seismic waves around $10 \mathrm{~Hz}$ are dominant at all the stations in A-type earthquakes. B-type earthquakes have frequency content from 1-6 Hz, lower than A-type earthquakes, at all the stations. The spectral characteristics are found at all the stations with different distances and directions, and this suggests that the observed spectra were caused by a source effect. 


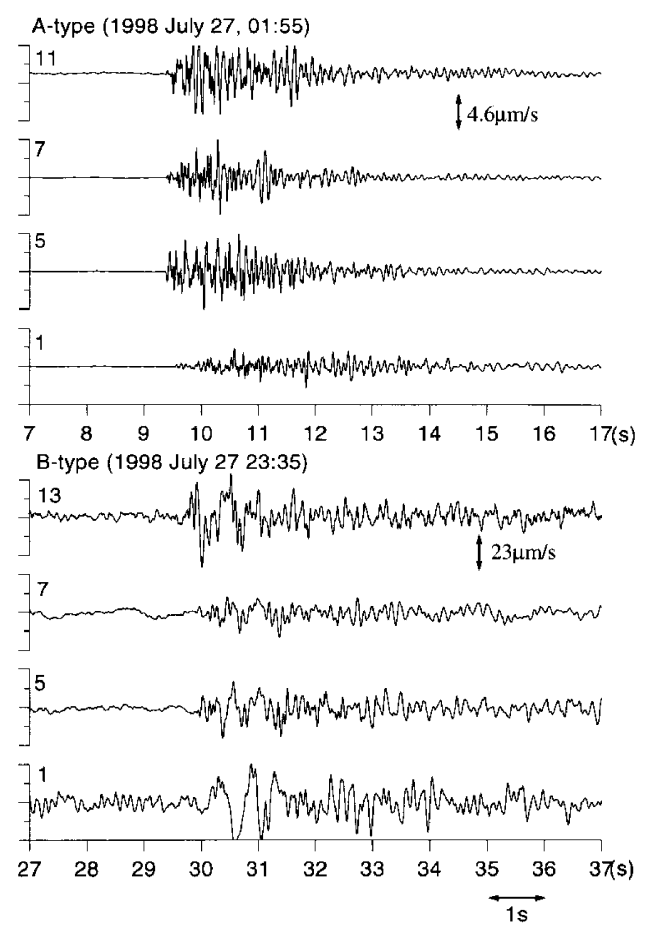

Fig. 2. Examples of typical waveforms of volcanic earthquakes observed at Satsuma-Iwojima. A-type earthquakes at 01:55 on July 27, 1998 (top), B-type earthquake at 23:35 on July 27, 1998 (bottom). All the traces were obtained by vertical components of seismometer. Numerals denote station code (Fig. 1).
Hypocenter locations of volcanic earthquakes were calculated using arrival times of $\mathrm{P}$-wave first motions at temporary stations on northern and western flank of the volcanoes (Fig. 1(B)), assuming homogeneous half space of $V_{p}=2.0$ $\mathrm{km} / \mathrm{s}$. No S-wave arrival times were used due to difficulty of precise picking up of them. Epicenters of A-type and Btype earthquakes are shown in Fig. 3. The distributions of epicenters of earthquakes obtained by $\operatorname{Kamo}(1976,1977)$ and Iguchi et al. (1999) are added to Fig. 3. Hypocenters of A-type earthquakes were distributed beneath the island, especially the northwestern flank of Mt. Iwodake at depth of $1 \mathrm{~km}$. In contrast, the epicenters of B-type earthquakes were concentrated beneath the summit crater of Mt. Iwodake. Focal depths of the B-type earthquakes were determined in the range from 0 to $4 \mathrm{~km}$. This scattered range of focal depths is due to the emergent onset of B-type earthquakes (Fig. 2). Particle motion diagram based on the velocity waveforms of 3-component seismograms shows that the P-wave first motion of B-type earthquake is nearly horizontally (Iguchi et al., 1999). This suggests the source of B-type earthquakes is located at very shallow depth, maybe above sea level.

Focal mechanisms of A-type earthquakes were determined from the first motion pattern of the P-waves. An Atype earthquake at 01:01 on November 22, 1999 is a welllocated event just north of the summit crater (Fig. 3). The polarities of $\mathrm{P}$-wave first motion at 19 stations are plotted on upper hemisphere of the focal sphere with an equal-area projection (Fig. 4). The P-wave first motions were dilatations at the stations near the summit crater, and those at the flank

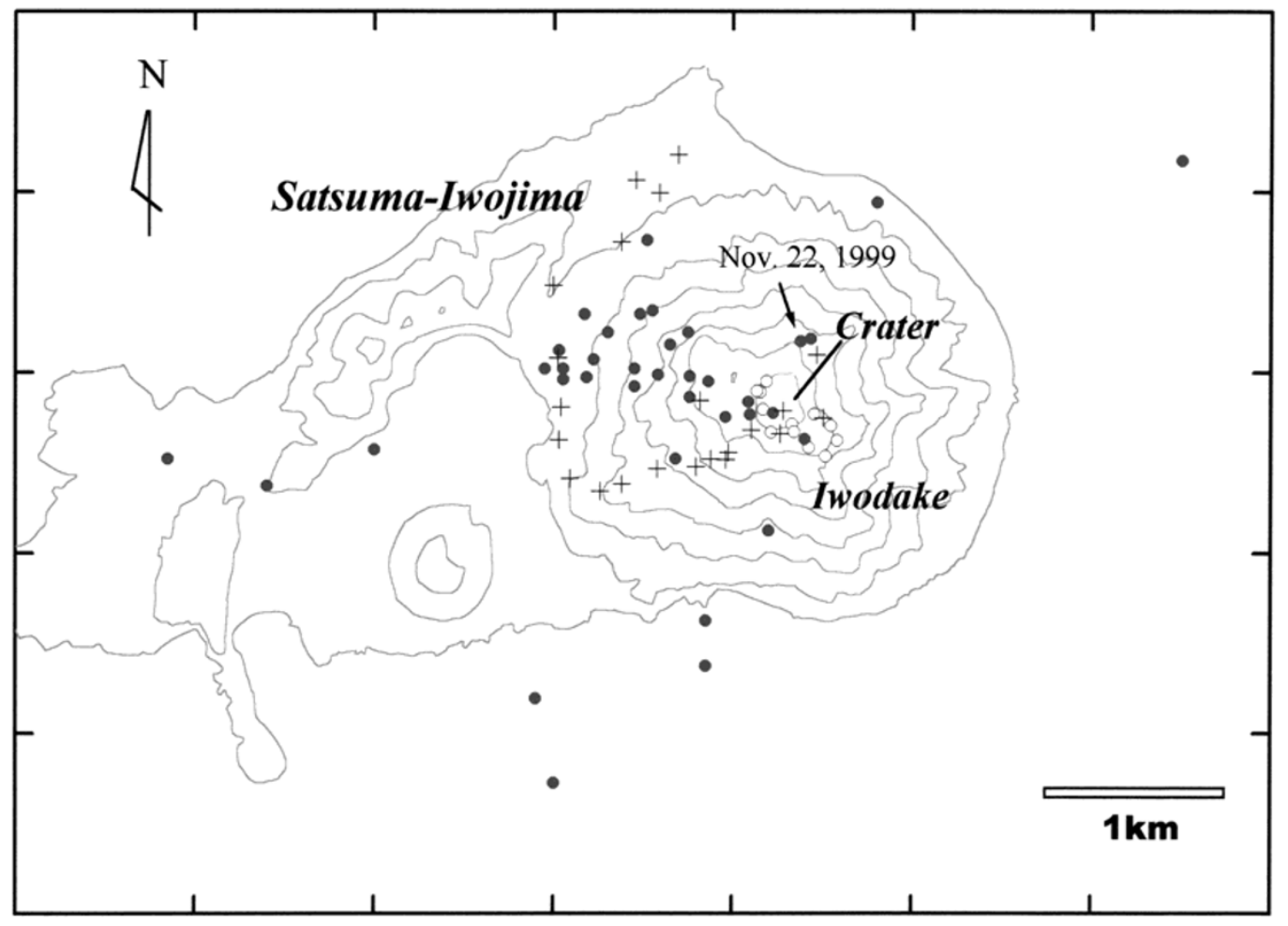

Fig. 3. Epicenter distribution of A-type and B-type earthquakes. Solid and open circles represent A-type and B-type earthquakes, respectively. The epicenter distribution is compiled from this study, Kamo $(1976,1977)$ and Iguchi et al. (1999). The epicenter of an earthquake at 01:01 on November 22, 1999 is indicated by arrow. Crosses represent seismic stations. 


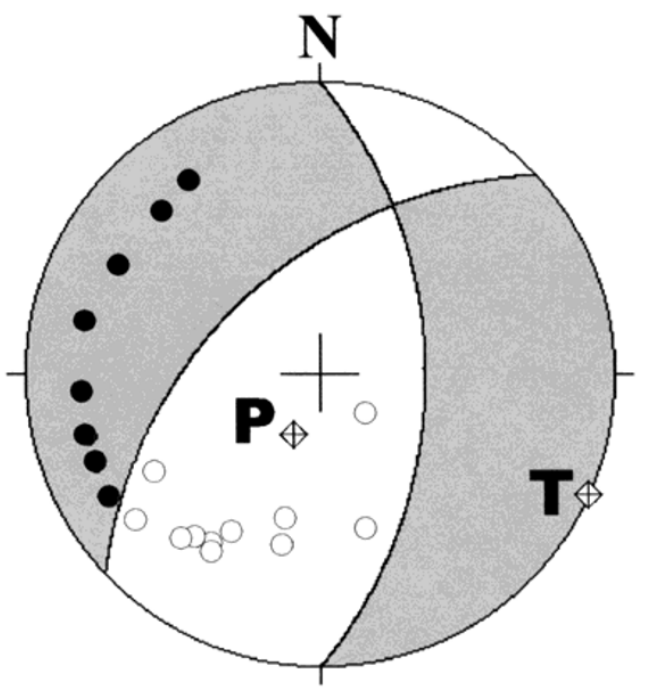

Fig. 4. Typical focal mechanism of A-type earthquake. A solution of focal mechanism of an A-type earthquake at 01:01 on November 22, 1999 is shown. Polarities of P-wave first motions are plotted on upper hemisphere of the focal sphere with equal area projection. Solid and open circles denote compression and dilatation of P-wave first motions, respectively. Diamonds represent directions of $\mathrm{P}$ and $\mathrm{T}$ axes. The focal mechanism indicates dominantly normal faulting with a small strike-slip component. were compressions. The focal pattern is a quadrantal type, typical of tectonic earthquake. The focal mechanism was estimated to be dominantly of normal fault-type with P-axis oriented nearly vertically and T-axis horizontally oriented to E-ESE. Hypocenters of A-type earthquakes are distributed at northwestern and north flank of Mt. Iwodake in November 1999. Although it is difficult to obtain unique solution of focal mechanisms from the stations of small number, the dilatational first motions were identified at stations close to the hypocenters and the first motions were compressions at further stations for most of the A-type earthquakes. The result shows normal fault type earthquakes are dominant at the volcano.

In contrast, B-type earthquakes have a different focal mechanism. The first motions of B-type earthquake were observed as compressions at all the stations. The distribution pattern of the first motion suggests volume expansion at the source. Moment tensor inversion (Kikuchi and Kanamori, 1991) for P-wave first motion shows that dominance of three diagonal components of moment tensor, and it is thought that B-type earthquake is initiated by volumetric expansion of the source (Iguchi et al., 1999).

\section{Comparison of Seismic Activity in 1995-1998 with that in 1976-1978}

We count the number of volcanic earthquakes with maximum amplitude larger than $16 \mu \mathrm{m} / \mathrm{s}$ and S-P time interval less than $2 \mathrm{~s}$ at the station IWO. The larger earthquakes were

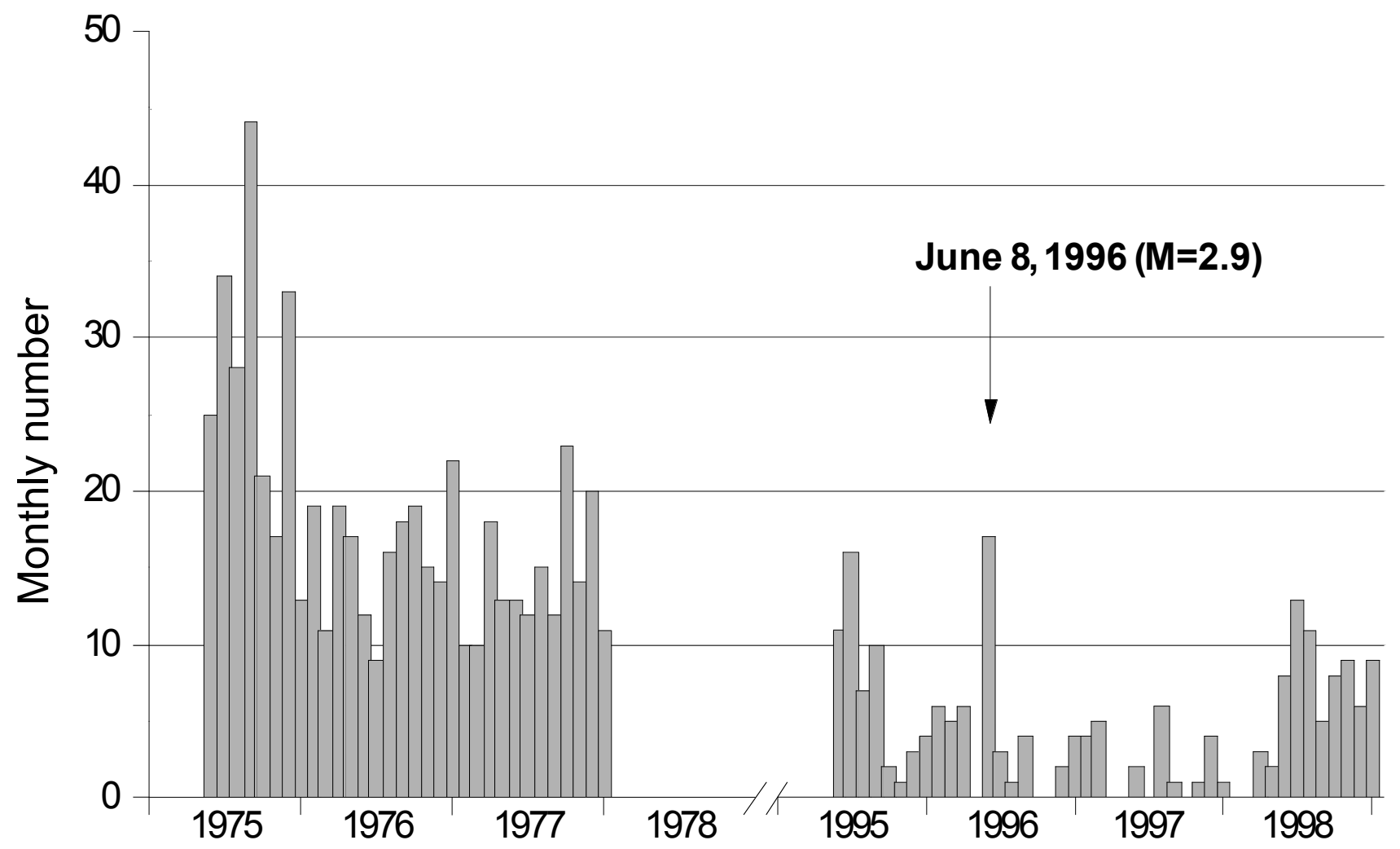

Fig. 5. Monthly number of volcanic earthquakes at the station IWO (Fig. 1(B)). The earthquakes with maximum amplitude of $>16 \mu$ m/s are counted. The numbers during the period from 1975 to 1978 were recorded at station C (Fig. 1(B)), and the maximum amplitudes have been corrected, taking into account of attenuation of seismic waveform due to geometric spreading to provide uniform data with 1995-1998. 


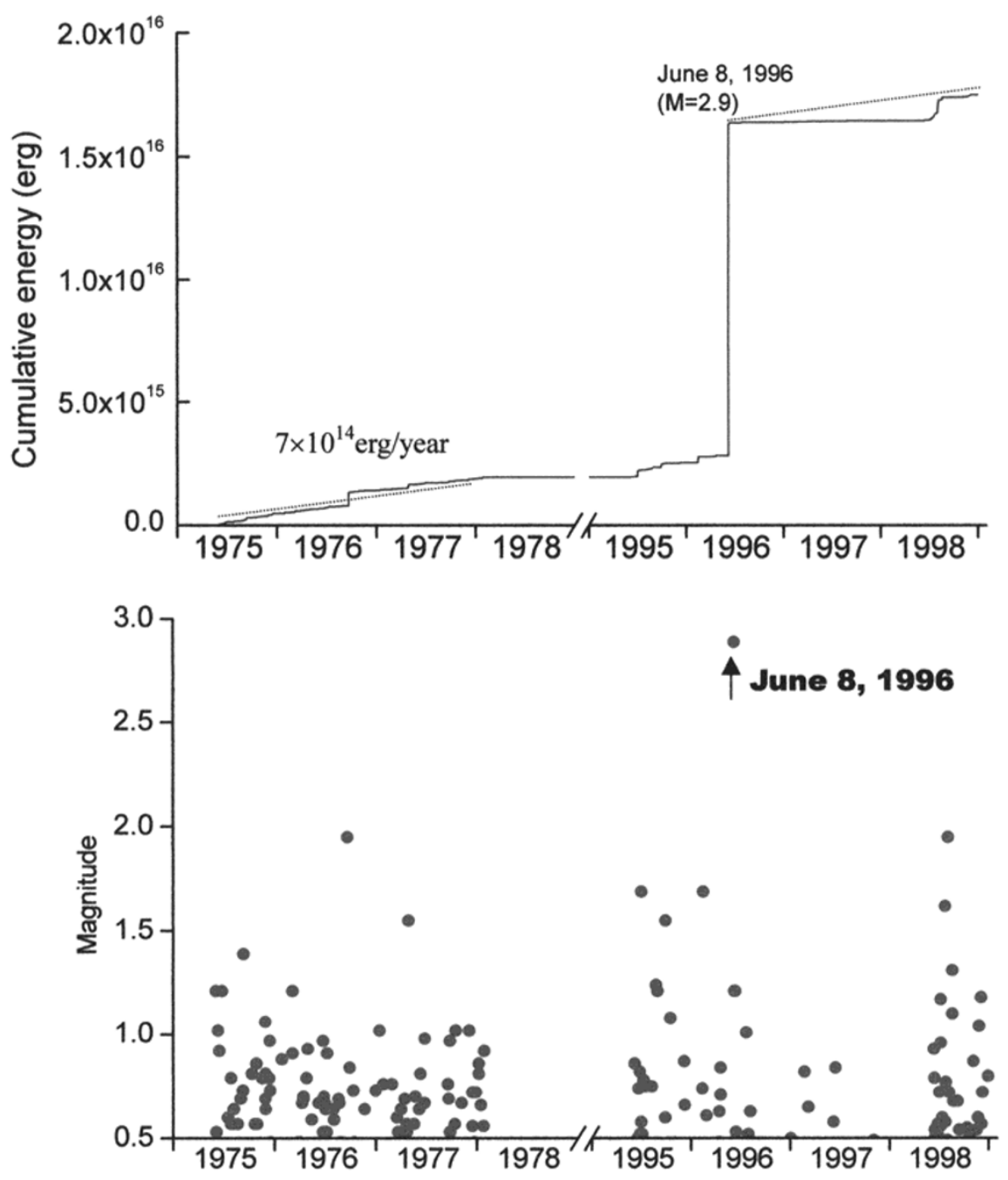

Fig. 6. Plots of magnitude (bottom) and cumulative of seismic energy (top) released by the A-type earthquakes at Satsuma-Iwojima during the periods in 1975-1978 and 1995-1998. Dashed lines denote seismic energy release rate of $7 \times 10^{14} \mathrm{erg} / \mathrm{year}$.

always A-type events. After June 1995, around 10 volcanic earthquakes occurred every month (Fig. 5). The seismicity in 1995-1998 is compared with that during the period from June 1975 to January 1978. Volcanic earthquakes with maximum amplitude of $>10 \mu \mathrm{m} / \mathrm{s}$ and S-P time interval of $<2$ s were counted in 1975-1978, and the earthquakes were also classified into A-type (Kamo, 1976, 1977, 1978). Although the monthly number of volcanic earthquakes sometimes reached more than 80 in September 1975, 10-30 volcanic earthquakes were observed in a month for most of the observation period. The seismic station C (Fig. 1) used for count of number of volcanic earthquakes in 1975-1978 was closer to the summit of Mt. Iwodake than station IWO. Here, we have adjusted number of earthquakes by correcting their amplitude using the attenuation of seismic waves due to geometric spreading. Monthly numbers of A-type earthquakes during the period from 1975 to 1978 and from 1995 to 1998 are shown in Fig. 5. Monthly numbers of A-type earthquakes were 20-40 in 1975 and 10-20 in 1976 and 1977. After June 1995, less than 10 volcanic A-type earthquakes also occurred in a month.

It is possible that change in monthly number was caused by change in location of hypocenters of the A-type earthquakes. To estimate seismicity more quantitatively, seismic energy released by the A-type earthquakes was calculated. The stations $\mathrm{C}$ and IWO, equipped with seismometers of the same frequency response, are located at west-northwestern flank of Satsuma-Iwojima, and the relation between the duration $(T)$ of an earthquake and its magnitude $(M)$ is obtained empirically as follows;

$$
M=4.25 \log _{10} T-0.4 \text {. }
$$

The seismic energy released by the earthquakes was calculated by the Gutenberg-Richter formula (Gutenberg and Richter, 1956). The magnitude and seismic energy release estimated for the earthquakes during the periods 1975-1978 and 1995-1998 are shown in Fig. 6. Magnitudes of the earthquakes were less than 2, except the earthquake on June 8,1996 . Most of the earthquakes have a magnitude of $<1$. Seismic energy release rates were about $7 \times 10^{14} \mathrm{erg} /$ year in both of the periods of 1975-1978 and 1995-1998, except the seismic energy increase caused by the earthquake on June 8, 1996. No felt earthquakes were reported at SatsumaIwojima volcano during the observation gap from February 
1978 to May 1995. Except for the earthquake on June 8, 1996 , nearly constant seismicity has continued for at least 20 years.

\section{Felt Earthquake on June 8, 1996}

During the period of stable seismicity in 1995-1998, a felt earthquake occurred at 21:06, on June 8, 1996. The seismic intensity of the earthquake was 2 in JMA scale at a village $3 \mathrm{~km}$ from Mt. Iwodake on Satsuma-Iwojima Island and the magnitude, M2.9, is larger than the other A-type earthquakes (Fig. 6). Hypocenter location was estimated to be near Satsuma-Iwojima Island by using $\mathrm{P}$ and $\mathrm{S}$ arrival times at stations of a larger seismic network in the southern part of Kyushu, and assuming a standard velocity structure model (Nishi and Iguchi, 1983). The S-P time interval of $0.5 \mathrm{~s}$ at the station IWO is the same as those of earthquakes which were located beneath Mt. Iwodake, and the particle motion of the first motion showed seismic waves that propagated from east. These data show that the event occurred beneath Mt. Iwodake.

Focal mechanism of the event was determined by using the first motion pattern of the P-waves at the stations in southern Kyushu. Polarities of P-wave first motion by equalarea projection on the lower hemisphere of the focal sphere are shown in Fig. 7. The first motion at the station IWO was dilatation, and those at distant stations were compressions. The focal mechanism of the event is poorly constrained but is clearly a normal fault type, which is dominant at SatsumaIwojima volcano.

We infer that the earthquake on June 8, 1996 was related to topographic changes and deformation around the summit crater of Mt. Iwodake observed about the same time.

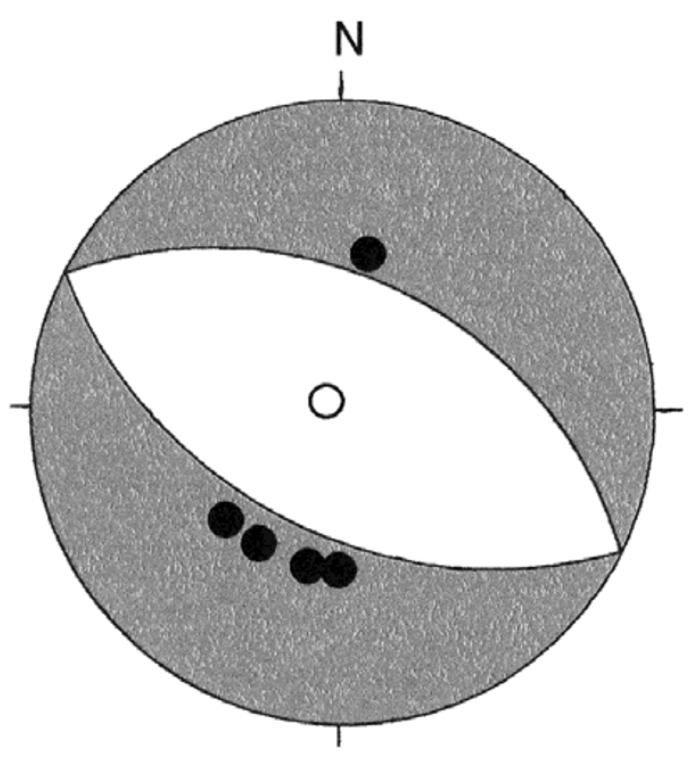

21:06 June 8, 1996

Fig. 7. Focal mechanism of A-type earthquakes at 21:06 on June 8, 1996. Polarities of $\mathrm{P}$-wave first motions are plotted on lower hemisphere of the focal sphere with equal area projection. Solid and open circles denote compression and dilatation of $\mathrm{P}$-wave first motions, respectively.
GSJ has made repeated observations of topographic changes and changes in fumarolic activity in and around the summit crater (Geological Survey of Japan, 1997). In 1990, fumaroles with high temperature (about $900^{\circ} \mathrm{C}$ ) were distributed on a slope near the rim of the summit crater. Fumaroles near the bottom of the crater became active in 1994 and the activity around the rim declined. In October 1996, GSJ staff found a new pit crater emitting jet-like sound at the crater bottom and a new crack with a length of $100 \mathrm{~m}$ at the southeastern rim.

Changes in slope distances are shown in Fig. 8 for baselines between station IWOG and several benchmarks on Satsuma-Iwojima. The slope distances of benchmarks at the flank have been stable since June 1995, however, slope distance between IWDK and IWOG increased by $6 \mathrm{~cm}$ in the period from June 1995 and April 1997. If IWOG is assumed to be fixed, IWDK moved $6 \mathrm{~cm}$ to the east-northeast (Fig. 8). IWDK is close to the crack at southeastern rim of the summit crater, and no remarkable changes were observed after April 1997. We infer that the displacement of IWDK was caused by formation of the crack. We also infer that the earthquake that occurred on June 8, 1996, 4 months before the new crack was found, is also related to formation of the crack. The ground on the crater-side of the crack subsided (Geological Survey of Japan, 1997) and this deformation is reflected by the normal fault type focal mechanism of the event. Vertical displacement is expected at IWDK from normal fault focal mechanism, however dominant horizontal displacement was observed at IWDK and vertical displacement was less than $1 \mathrm{~cm}$ within errors of measurement by GPS. The movement of the crack also includes horizontal expansion of $30 \mathrm{~cm}$ (Geological Survey of Japan, 1997). It is interpreted that the vertical displacement was concentrated beside the crack due to shallowness of a deformation source and only horizontal movement of the crack affected the displacement of IWDK benchmark, which is located $200 \mathrm{~m}$ apart from the crack. It is reported that the June 1996 earthquake was accompanied by a sound (per. comm. Mr. Orita, resident on the island). It is possible that the sound associated with the earthquakes was generated by the fracture zone reaching ground surface beside the southeastern rim of the crater.

A probable model is shown in Fig. 9. Shinohara et al. (2002) interpreted an increase in $\mathrm{SO}_{2}$ flux, and maximum and equilibrium temperatures of volcanic gas from the summit crater in mid-1990's as caused by ascent of a magma column. Pressure beneath the crater temporarily increased as a result of ascent of the magma column, however, the pressure may have decreased after a large amount of volcanic gas was emitted. The normal fault earthquake on June 8, 1996 may have been generated by subsidence of the ground of the crater due to this pressure decrease beneath the crater, and the fault reached the ground surface. As a result, a crack was formed at southeastern rim of the summit crater and volcanic gas was also emitted through the fault, expanding the crack.

The relation between magnitude $(M)$ and moment $\left(M_{0}\right)$ for micro earthquakes is obtained as follows (Iio, 1986);

$$
\log M_{0}=1.37 M+16.2 .
$$


Earthq. June 8, 1996

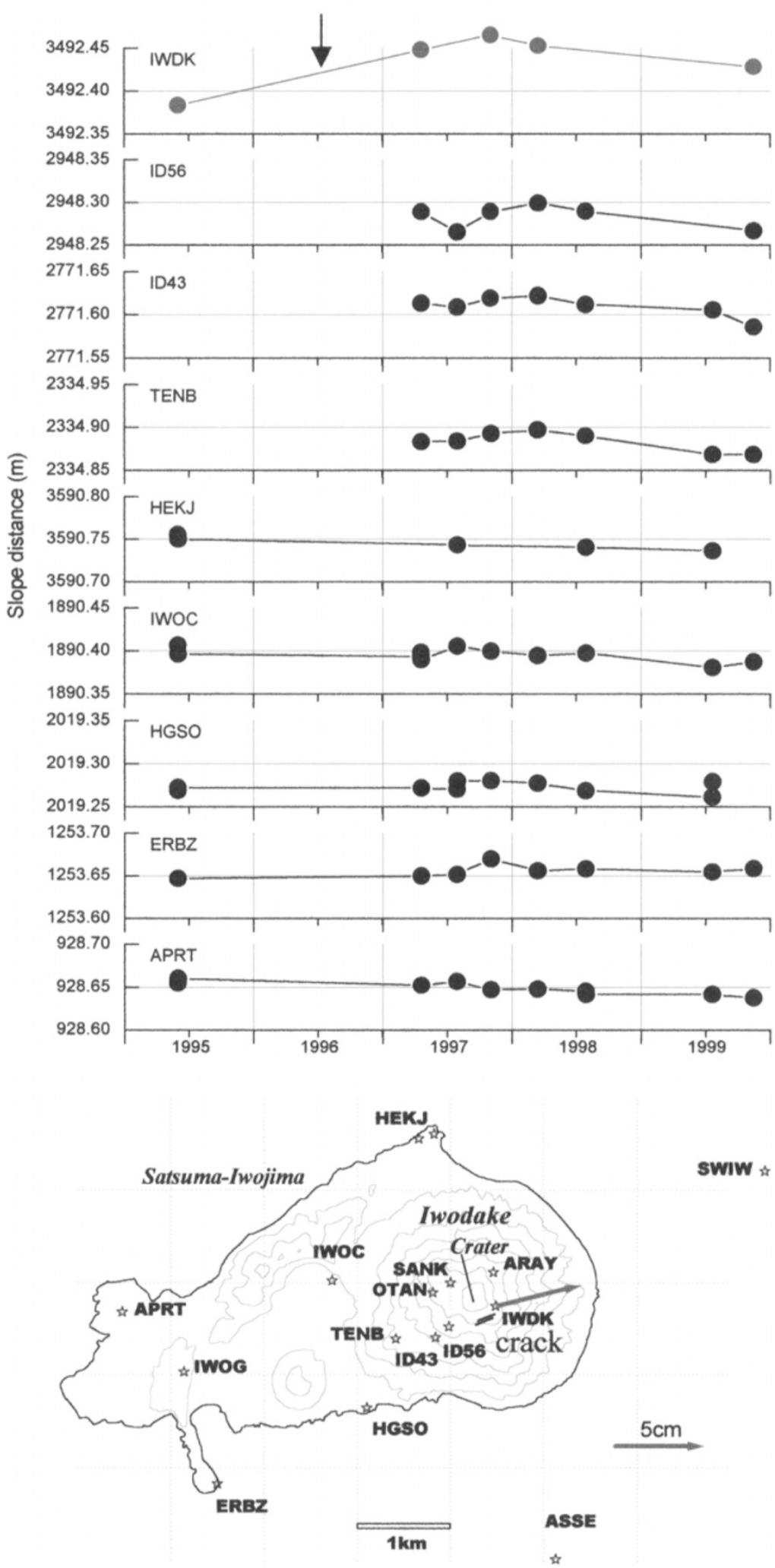

Fig. 8. Changes in slope distances measured by GPS (top). All measurements are relative to the base station at IWOG. Displacement vector at IWDK site during the period from June 1995 to April 1997 is shown at the bottom. 


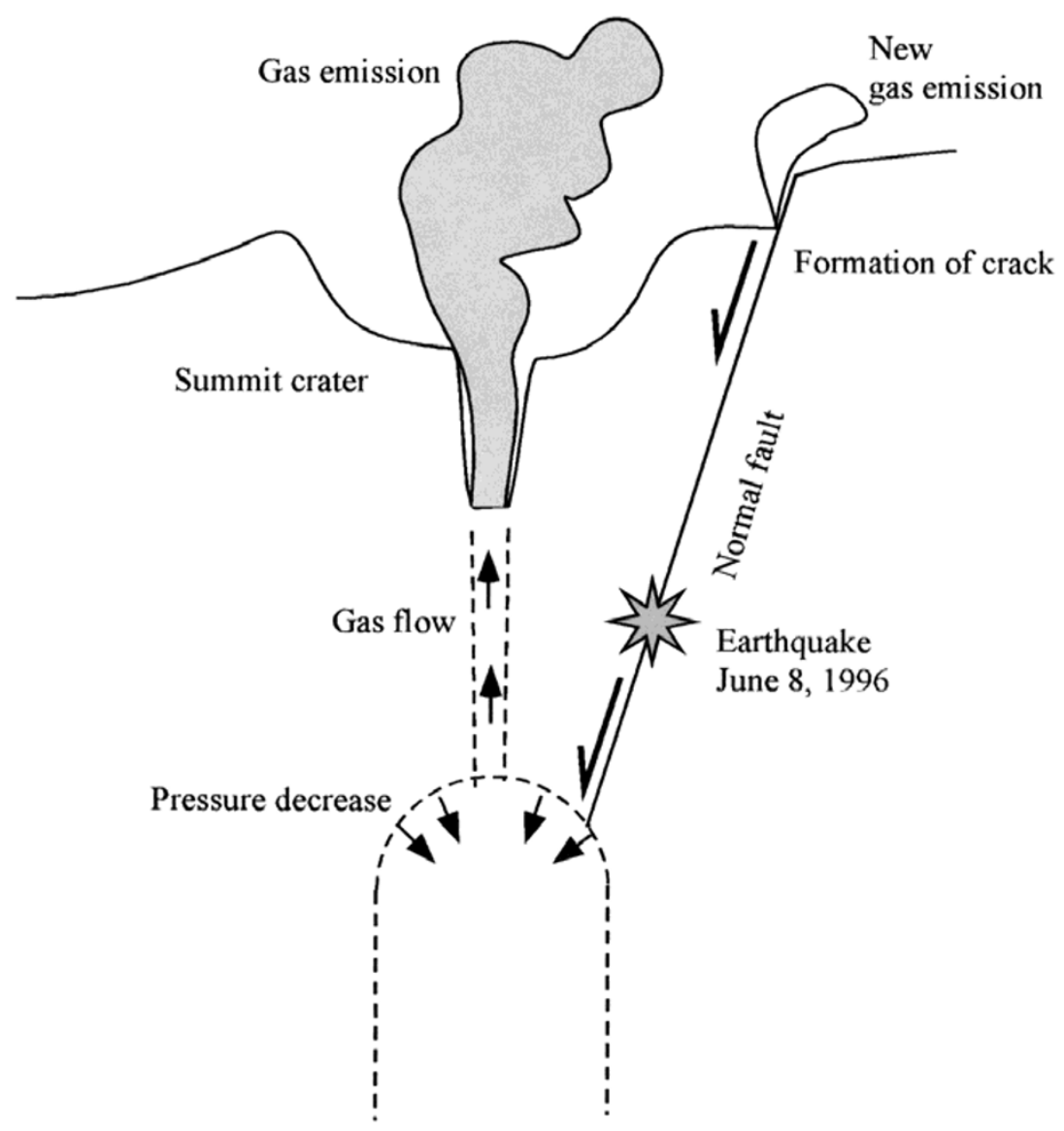

Fig. 9. A probable model for occurrence of earthquake on June 8, 1996 and formation of the crack. The crack was found at southeastern rim of the summit crater in October 1996, after the earthquake occurred. The pressure beneath the crater decreased due to the emission of volcanic gas. The ground in the crater subsided due to the pressure decrease, generating the normal fault earthquake. Volcanic gas was newly emitted through the fault and the crack.

The moment of the earthquake on June 8, 1996 was calculated to be $5 \times 10^{20} \mathrm{dyn} \cdot \mathrm{cm}$. From the plots of moment tensor versus source radius (Harr et al., 1984), the source radius is estimated to be around $10^{2} \mathrm{~m}$. It is therefore possible that an earthquake of M2.9 could create a crack with a length of $100 \mathrm{~m}$.

Except one earthquake with M2.9, seismicity during the period from 1995 to 1998 was almost stable. The seismicity of the period was not so different from that in 1975-1978. The seismicity at the volcano has been stable for the last 20 years. The stable seismicity at Satsuma-Iwojima volcano coincides with stable volcanic activity estimated by analysis volcanic gas and temperature measurement of fumarolic gas (Shinohara et al., 2002).

It was reported that number of volcanic earthquakes increased from September 1998 and the daily numbers reached 150-200 after end of October 1998 (Iguchi et al., 1999). The volcanic earthquakes were dominated by B-type events. The maximum amplitudes of the earthquakes were $<10 \mu \mathrm{m} / \mathrm{s}$ (p-p) and were much smaller than those of Atype earthquakes treated in the previous section. Although the numbers increased, the seismic energy released by Btype earthquakes is much smaller than those of A-type earthquakes due to smaller amplitude and lower frequency. The increase in B-type earthquake does not severely affect cumulative seismic energy curve shown in Fig. 6.
During increase in the number of volcanic earthquakes, ash fall was sometimes observed at Satsuma-Iwojima and Takeshima Island, $10 \mathrm{~km}$ east of Mt. Iwodake, however, ash emission was also observed even in rather seismically lower period in July 1998 and it is thought that the ash and gas emission from the summit crater almost continuously occur after. Shinohara et al. (2002) pointed out that the volcanic ash ejected from the crater was not fresh and was the result of a strong flow of volcanic gas suspending and carrying up the accumulated material in the crater bottom. The increase in the number of volcanic earthquake in September and October 1998 did not accompany any change in volcanic activity, such as an increase in $\mathrm{SO}_{2}$ flux, highest temperature and equilibrium temperature of gas from the summit crater (Shinohara et al., 2002). Remarkable ground deformation was not detected associating with the increase in the number of B-type earthquakes (Fig. 7). As it is inferred that B-type earthquakes are generated by volumetric source related to gas expansion (Iguchi et al., 1999), increases in the number of B-type earthquake may reflect fluctuations in conditions in the gas conduit.

\section{Conclusion}

Seismic observation shows almost stable activity at Satsuma Iwojima volcano in the last 20 years. The only expansion to this was a felt earthquake with M2.9 on June 8, 1996. 
The earthquake occurred due to a decrease in pressure beneath the crater and formed a crack at the southeastern rim of the crater. Measurable ground movement accompanied the event.

Acknowledgments. The authors appreciate Nanto Opal Company, especially Mr. Nagahama and Mr. Tokuda who permitted us to enter the crater area and helped with our observations. Mishima village office also supported observation and maintenance of the system. Staff member of SVO, DPRI, Kyoto University maintained continuous observation system. FDMO kindly shared their seismic signal to our telemetering system. Discussions with Drs. Hiroshi Shinohara and Kohei Kazahaya, GSJ are valuable. Mr. Kiyoshi Nishi, SVO, Kyoto University read the manuscript. The comments by Drs. Steven Sherburn and an anonymous reviewer are very helpful to revise the manuscript.

\section{References}

Geological Survey of Japan, Recent volcanic activity at the summit of Iwodake, Satsuma-Iwojima, Rep. Cood. Comm. Pred. Volc. Erup., 67, 79-82, 1997 (in Japanese).

Gutenberg, B. and C. F. Richter, Magnitude and energy of earthquakes, Ann. Geofis., 9, 1-15, 1956.

Hamada, N., H. Jingu, and K. Ikumoto, On the volcanic earthquakes with slowly decaying coda wave, Bull. Volcanol. Soc. Jpn., 21, 167-183, 1976 (in Japanese with English abstract).

Harr, L., J. B. Fletcher, and C. S. Mueller, The 1982 Enola, Arkansas, swarm and scaling of ground motion in the eastern United States, Bull. Seism. Soc. Am., 74, 2463-2482, 1984.

Iguchi, M., Geophysical data collection using an interactive personal computer system (part 1) -Experimental monitoring at Suwanosejima Volcano-, Bull. Volcanol. Soc. Jpn., 36, 335-343, 1991.

Iguchi, M., K. Ishihara, T. Takayama, T. Tamekuri, H. Shinohara, and E. Saito, Volcanic activity at Satsuma-Iwojima during 1995-1998, Ann. Disas. Prev. Res. Inst., Kyoto Univ., 42B-1, 1-10, 1999 (in Japanese with English abstract).
Iio, Y., Scaling relation between earthquake size and duration of faulting for shallow earthquakes in seismic moment between $10^{10}$ and $10^{25}$ dyne.cm, J. Phys. Earth, 34, 127-169, 1986.

Kamo, K., Seismic observation, in Feasibility study on volcano electric power plant. Research Report of commissioned survey on Sunshine project, 28-59, 1976 (in Japanese).

Kamo, K., Seismic observation, in Feasibility study on volcano electric power plant. Research Report of commissioned survey on Sunshine project, 25-39, 1977 (in Japanese).

Kamo, K., Seismic observation, in Feasibility study on volcano electric power plant. Research Report of commissioned survey on Sunshine project, 17-31, 1978 (in Japanese).

Kamo, K., M. Iguchi, and K. Ishihara, Inflation of volcano Sakurajima detected by automated monitoring system of GPS network, in Proc. Int. Symp. Current crustal movement and hazard reduction, Wuhan RP. China, 1997, 629-640, 1997.

Kikuchi, M. and H. Kanamori, Inversion of complex body waves-III, Bull. Seis. Soc. Am., 81, 2335-2350, 1991.

Matsumoto, T., The four giantic caldera volcanoes of Kyushu, Jap. Jour. Geol. Geogra, 19, 57, 1943.

Nishi K. and M. Iguchi, Preliminary report on the seismicity in South Kyushu, Ann. Disas. Prev. Res. Inst., Kyoto Univ., 26B-1, 23-29, 1983 (in Japanese with English abstract).

Ohminato, T. and D. Ereditato, Broadband seismic observations at Satsuma-Iwojima volcano, Japan, Geophys. Res. Lett., 24, 2845-2848, 1997.

Shinohara, H., K. Kazahaya, G. Saito, N. Matsushima, and Y. Kawabe, Degassing activity from Iwodake rhyolitic cone, Satsuma-Iwojima volcano, Japan: Formation of a new degassing vent, 1990-1999, Earth Planets Space, 54, this issue, 175-185, 2002.

Uchida, N. and T. Sakai, Analysis of peculiar volcanic earthquakes at Satsuma-Iojima volcano, Earth Planets Space, 54, this issue, 197-209, 2002.

M. Iguchi (e-mail: iguchi@svo.dpri.kyoto-u.ac.jp), E. Saito, Y. Nishi, and T. Tameguri 